\title{
ON THE JUSTIFICATIONS FOR CIVIL COMMITMENT *
}

\author{
JosepH M. LIVERMore, $\dagger$ Card P. MaLmquist, $\dagger$ \\ and PaUd E. MEemL $\dagger \dagger$
}

Involuntary confinement is the most serious deprivation of individual liberty that a society may impose. The philosophical justifications for such a deprivation by means of the criminal process have been thoroughly explored. No such intellectual effort has been directed at providing justifications for societal use of civil commitment procedures. $^{1}$

When certain acts are forbidden by the criminal law, we are relatively comfortable in imprisoning those who have engaged in such acts. We say that the imprisonment of the offender will serve as an example to others and thus deter them from violating the law. If we

* Our reflections on the justifications for civil commitment were greatly aided and in part actuated by the excellent collection of material in J. KATZ, J. GoLDSTEIN \& A. Dershowitz, Psychoanalysis, Psychiatry and Law (1967). See also T. Szasz, LAw, LIBERTy ANd Psychratry (1963) ; Dershowitz, Psychiatry in the Legal Process: $A$ Krife That Cuts Both Ways, 4 TRIAI, Feb./Mar. 1968, at 29. The latter article is particularly perceptive.

$\dagger$ Associate Professor of Law, University of Minnesota. A.B. 1958, Dartmouth College. LL.B. 1961, Stanford University.

it Associate Professor of Psychology and Child Development, University of Minnesota. B.A. 1952, M.D. 1958, M.S. 1961, University of Minnesota. Psychiatric Consultant, Hennepin County (Minnesota) District Courts.

itt Professor of Psychology, College of Liberal Arts; Professor of Clinical Psychology, Department of Psychiatry, Medical School, University of Minnesota. B.A. 1941, Ph.D. 1945, University of Minnesota.

1 But see Ross, Contmitment of the Mentally Ill: Problems of Law and Policy, 57 Mich. L. REv. 945, 954-964 (1959). It will become obvious that we share the point of view of C. S. Lewis and Francis Allen that confinement is confinement regardless of the name under which it parades.

To be taken without consent from my home and friends; to lose my liberty; to undergo all those assaults on my personality which modern psychotherapy knows how to deliver; to be re-made after some pattern of "normality" hatched in a Viennese laboratory to which I never professed allegiance; to know that this process will never end until either my captors have succeeded or I have grown wise enough to cheat them with apparent success-who cares whether this is called Punishment or not?

Lewis, The Humanitarian Theory of Punishment, 6 Res Judicatae 224, 227 (1953).

Measures which subject individuals to the substantial and involuntary deprivation of their liberty contain an inescapable punitive element, and this reality is not altered by the fact that the motivations that prompt incarceration are to provide therapy or otherwise contribute to the person's well-being or reform. As such, these measures must be closely scrutinized to insure that power is being applied consistently with those values of the community that justify interference with liberty for only the most clear and compelling reasons. F. Alten, The Borderland of Criminal Justice 37 (1964). 
even stop to consider the morality of depriving one man of his liberty in order to serve other social ends, we usually are able to allay anxiety by referring to the need to incarcerate to protect society from further criminal acts or the need to reform the criminal. When driven to it, at last, we admit that our willingness to permit such confinement rests on the notion that the criminal has justified it by his crime. Eligibility for social tinkering based on guilt, retributive though it may be, has so far satisfied our moral sensibilities. ${ }^{2}$

It is, we believe, reasonably clear that the system could not be justified were the concept of guilt not part of our moral equipment. Would we be comfortable with a system in which any man could go to jail if by so doing he would serve an overriding social purpose? The normal aversion to punishment by example, with its affront to the principle of equality, suggests that we would not. Conversely, could we abide a rule that only those men would be punished whose imprisonment would further important social ends? Again, the thought of vastly different treatment for those equally culpable would make us uneasy. ${ }^{3}$

Similarly, if we chose to justify incarceration as a means of isolating a group quite likely to engage in acts dangerous to others, we would, without the justification of guilt, have difficulty explaining why other groups, equally or more dangerous in terms of actuarial data, are left free. By combining background environmental data, we can identify categories of persons in which we can say that fifty to eighty per cent will engage in criminal activity within a short period of time. ${ }^{4}$

2 See generally H. L. A. Hart, Punishment and Responsibility (1968); H. M. Hart, The Aims of the Criminal Law, 23 LAw \& Contemp. ProB. 401 (1958).

3 Of course, arbitrary punishment would lose its utility if its nature were widely known, but even if it were useful it would generally be viewed as morally wrong. See H. L. A. Hart, Punishment and Responsibility 77-80 (1968). Perhaps the reason that inequality in application can exist in the civil commitment area is that, like secret, arbitrary punishment, it does not make us conscious of any threat to our own liberty.

4 See Briggs, Wirt \& Johnson, An Application of Prediction Tables to the Study of Delinquency, 25 J. Consulting Psychology 46 (1961); Craig \& Glick, A Manual of Procedure for Application of the Ghueck Prediction Table, in J. Katz, J. GoLDStein \& A. Dershowitz, Psychoanalysis, Psychiatry and Law 39499 (1967); Thompson, A Validation of the Glueck Social Prediction Scale for Proneness to Delinquency, 43 J. CRIM. L.C. \& P.S. 451 (1952). But see S. Hathawax \& E. MonaChesi, Adolescent Personality and Behayior: MMPI Patterns of Normal, Delinguent, Dropout, and Other Outcomes (1963); S. Hathaway \& E. Monachesi, An Atlas of Juvenile MMPI Profiles (1961); S. Hathaway \& E. MonaChesi, Analyzing and Predicting Juvenile Delinguency wite the MMPI (1951); Wirt \& Briggs, The Efficacy of Ten of the Glueck's Predictors, 50 J. CRIM. L.C. \& P.S. 478 (1960). See generally Briggs \& Wirt, Prediction, in JuVEnLle Delinguency, RESEARCH AND THEORY 170 (H. Quay ed. 1965).

In addition to the legal, ethical, and social policy issues upon which we focus in this paper, there is a difficult problem concerning the application of actuarial results to the disposition of the individual case. In the text we have simply referred to the betting odds, the "chances per hundred" that behavior of a stated kind will subsequently occur, without examining such questions as how such numerical estimates are 
If social protection is a sufficient justification for incarceration, this group should be confined as are those criminals who are likely to sin again. ${ }^{5}$

The same argument applies when rehabilitative considerations are taken into account. Most, if not all of us could probably benefit from some understanding psychological rewiring. Even on the assumption that confinement should be required only in those cases where antisocial acts may thereby be averted, it is not at all clear that criminals are the most eligible for such treatment. In addition, most people would

best arrived at, or what should be their precise interpretation when applied to an individual. To go into the logical, epistemological and mathematical issues involved therein (e.g., the very technical controversy over the several alleged meanings of the word "probability") is beyond the scope of this paper. The leading treatment of the so-called "clinical-statistical" issue in the behavioral sciences is P. MEEHL, ClinICAL Versus Statistical Prediction (1954). See also G. Kimble \& N. Garmezy, PrinCiples of General Psychology 589 (3d ed. 1968); B. Kleinmuntz, Personality Measurement 344 (1967); P. Marks \& W. Seeman, Tae Actuarial Description of Abnoraral Personaltry (1963) ; Research in Clrnical Assessment (E. Megargee ed. 1966); W. Mischel, Personality and Assessment 128 (1968) ; N. Sundberg \& L. Tyler, Clinical Psychology: An Introduction to Research and PracTICE 197-224 (1962); Gough, Clinical Versus Statistical Prediction in Psychology, in Psychology in THE Making 526 (L. Postman ed. 1962); Kleinmuntz, The Processing of Clinical Information by Man and Machine, in FoRMAL REPRESENTATION OF Human Judgment 149 (B. Kleinmuntz ed. 1968); Meehl, What Can the Clinician Do Well? in Problems in Human Assessment 594 (D. Jackson \& S. Messick eds. 1967); Meeh1, When Shall We Use Our Heads Instead of the Formula? 4 J. CounSELING PSYCHOLOGY 268 (1957). Without digressing into the merits of that controversy, we cannot avoid at least entering two caveats for the benefit of our law-trained readers who will, in general, be unfamiliar with the relevant research literature, by now very considerable in scope. First, one should not simply assume as somehow obvious that "individual prediction" is fundamentally different from "actuarial prediction," a quick-and-easy distinction very commonly. presupposed in many quarters. Second, one should not simply assume that "intensive, clinical, psychological understanding of the individual" leads generally to more trustworthy forecast of behavior than a more behavioristic-actuarial approach to the predictive task. This second assumption seems still to be taken blithely for granted by almost all psychiatrists andsurprisingly, given the research evidence-by many clinical psychologists. The comparative efficacy of different methods of predicting behavior is, of course, a factual question; and in spite of the armchair plausibility of the above mentioned assumptions (to be sceptical of "understanding the individual" is rather like being against motherhood), there exists a very sizable body of empirical evidence to the contrary. The latest published summary of factual evidence is Sawyer, Measurement and Prediction, Clinical and Statistical, 66 PSYCHOLOGICAL BuLL. 178 (1966), which also presents a very sophisticated and fair-minded methodological reformulation. Of some five dozen published and unpublished research studies known to us, there is only a single study showing, given an acceptable research design, a clearcut superiority of clinical judgment over actuarial prediction. See Lindzey, Seer Versus Sign, 1 J. ExPERIMENTAL Researce IN PERSonality 17 (1965); Meeh1, Seer Over Sign: The First Good Example, $1 \mathrm{~J}$. EXPERIMENTAL Research in PeRsonality 27 (1965). But see Goldberg, Seer Over Sign: The First "Good" Example? 3 J. ExPERIMENTAL Research in PERSONALITY - (1968). It would be difficult to mention any other domain of social science research in which the trend of the data is so uniformly in the same direction, so that any psychiatrist or psychologist who disfavors the objective, actuarial approach in a practical, decision-making context should be challenged to show his familiarity with this research literature and invited to rebut the theoretical argument and empirical evidence found therein.

5 The habitual criminal statutes may be thought of as one instance where incarceration is based on a judgment that the person incarcerated is dangerous. But such statutes also serve a deterrent function by a Benthamite increase in punishment for those who are viewed as especially likely to commit a crime. 
bridle at the proposition that the state could tamper with their minds whenever it seemed actuarially sound to do so.

Fortunately, we can by reason of his guilt distinguish the criminal from others whom we are loathe to confine. He voluntarily flouted society's commands with an awareness of the consequences. Consequently, he may serve utilitarian purposes without causing his imprisoners any moral twinge.

This same sort of analysis is not available once we move beyond the arena of the criminal law. When people are confined by civil process, we cannot point to their guilt as a basis for differentiating them from others. What can we point to?

The common distinguishing factor in civil commitment is aberrance. Before we commit a person we demand either that he act or think differently than we believe he should. Whether our label be inebriate, ${ }^{6}$ addict, ${ }^{7}$ psychopath, ${ }^{8}$ delinquent, ${ }^{9}$ or mentally diseased, ${ }^{10}$ the core concept is deviation from norms. ${ }^{11}$ Our frequently expressed value

6 See, e.g., Conn. Gen. Stat. Rev. \$17-155e (Supp. 1965).

7 E.g., ALA. CoDe tit. 22, \$\$249-50 (1958); see In re Spadafora, 54 Misc. 2d 123, 281 N.Y.S.2d 923 (Sup. Ct. 1967).

8 E.g., Boutilier v. Immigration \& Naturalization Service, 387 U.S. 118 (1967); Mrnn. Stat. Ann. \$ 526.09 (1947). See Minnesota ext rel. Pearson v. Probate Court, 309 U.S. 270 (1940).

9 E.g., MD. Code ANN. art. 31B, \&5 (1967); see Sas v. Maryland, 334 F.2d 506 (4th Cir. 1963); Director of Patuxent Institution v. Daniels, 243 Md. 16, 221 A.2d 397 (1966), cert. denied, 385 U.S. 940 (1966).

10 E.g., Mass. Ann. Laws ch. 123, §1 (1965) :

"Mentally ill" person, for the purpose of involuntary commitment to a mental hospital or school under the provisions of this chapter, shall mean a person subject to a disease, psychosis, psychoneurosis or character disorder which renders him so deficient in judgment or emotional control that he is in danger of causing physical harm to himself or to others, or the wanton destruction of valuable property, or is likely to conduct himself in a manner which clearly violates the established laws, or ordinances, conventions or morals of the community.

11 The concept "abnormal" or "aberrant" is sorely in need of more thorough logical analysis than it has, to our knowledge, as yet received. It seems fairly clear that several components-perhaps even utterly distinct kinds of meaning-can be discerned in the current usage of medicine and social science. The most objective meaning is the purely statistical one, in which "abnormal" designates deviation from the (statistical) "norm" of a specified biological or social population of organisms. Whether an individual specimen, or bit of behavior, is abnormal in this sense is readily ascertained by adequate sampling methods plus a more or less arbitrary choice of cutting score (e.g., found in less than 1 in 100 cases). But for legal purposes this purely statistical criterion does not suffice, because the kind and direction of statistical deviation from population norms, as well as the amount of deviation which threatens a protected social interest sufficiently to justify legal coercion, are questions not answerable by statistics alone. Thus, anyone who has an IQ of 180 , or possesses absolute pitch, or is color-blind, is statistically abnormal but hardly rendered thereby a candidate for incarceration, mandatory treatment, or deprivation of the usual rights and powers of a "normal" individual. A second component in the concept of normality relies upon our (usually inchoate or implicit) notions of biological health, of a kind of proper functioning of the organism conceived as a teleological system of organs and capacities. From a biological viewpoint, it is not inconsistent to assert that a sizable proportionconceivably a majority - of persons in a given population are abnormal or aberrant. 
of individual autonomy, however, renders us unable to express those norms, however deeply they may be felt, in criminal proscriptions. We could not bring ourselves to outlaw senility, or manic behavior, or strange desires. Not only would this violate the common feeling that one is not a criminal if he is powerless to avoid the crime, but it might also reach conduct that most of us feel we have a right to engage in. When a man squanders his savings in a hypomanic episode, we may say, because of our own beliefs, that he is "crazy," but we will not say that only reasonable purchases are allowed on pain of criminal punishment. We are not yet willing to legislate directly the Calvinist ideal.

What we are not willing to legislate, however, we have been willing to practice through the commitment process. That process has been used to reach two classes of persons, those who are mentally ill and dangerous to themselves or others ${ }^{12}$ and those who are mentally ill and in need of care, custody or treatment. ${ }^{13}$ While those terms seem reasonably clear, on analysis that clarity evaporates.

Thus, if an epidemiologist found that $60 \%$ of the persons in a society were afflicted with plague or avitaminosis, he would (quite correctly) reject an argument that "Since most of them have it, they are okay, i.e., not pathological and not in need of treatment." It is admittedly easier to defend this non-statistical, biological-fitness approach in the domain of physical disease, but its application in the domain of behavior is fraught with difficulties. See W. SchofIELd, PsychotherApY: THE PURCHASE OF FRIENDSHIP 12 (1964). Yet even here there is surely something to be said for it in extreme cases, as, for example, the statistically "normal" frigidity of middleclass Victorian women, which any modern sexologist would confidently consider a biological maladaptation in need of repair, induced by "unhealthy" social learnings. A third component invokes some sort of subjective norm, such as an aesthetic, religious, ethical, or political ideal or rule. Finally, whether an a priori concept of "optimal psychological adjustment" should be considered as yet a fourth meaning of normality, or instead subsumed under one or more of the preceding, is a difficult question. In any event, it is important to keep alert to hidden fallacies in legal and policy arguments that rely upon the notion of abnormality or aberration, such as subtle transitions from one of these criteria to another. It is especially tempting to the psychiatrist or clinical psychologist, given his usual clinical orientation, to slip unconsciously from the idea of "sickness," where treatment of a so-called "patient" is the model, to an application that justifies at most a statistical or ideological or psychological-adjustment usage of the word "norm." Probably the most pernicious error is committed by those who classify as "sick" behavior that is aberrant in neither a statistical sense nor in terms of any defensible biological or medical criterion, but solely on the basis of the clinician's personal ideology of mental health and interpersonal relationships. Examples might be the current psychiatric stereotype of what a good mother or a healthy family must be like, or the rejection as "perverse" of forms of sexual behavior that are not biologically harmful, are found in many infra-human mammals and in diverse human cultures, and have a high statistical frequency in our own society. See generally F. BEACH, SEXUAL BEHAVIOR IN ANIMALS AND MEN (1950); H. Ellis, Studies in the Psychology of Sex (1936); C. Ford \& F. Beach, Patterns of Sexual Behavior (1951); A. Kinsey, W. Pomeroy \& C. Martin, Sexual Behavior in the Human Male (1948); A. Kinsey, W. Pomeroy, C. Martin \& P. Gebhard, Sexual Behavior in the Human Female (1953); W. Masters \& W. Johnson, HunaA Sexual Response (1966); Ellis, What is "Normal" Sextual Behavior, 28 SEXology 364 (1962); S. FREUD, Three Essays on the Theory of Sexnality, in 7 COAIPLETE Psychological WORKs 123 (J. Strachey ed. 1962).

12 E.g., Tenn. Code AnN. \$33-604(d) (1967).

13 Id. For a discussion of standards applied in the various states, see AMrerican Bar Foundation, The Mentally Disabled and the Law 17, 44-51 (1961). 


\section{Mental Illness}

One need only glance at the diagnostic manual of the American Psychiatric Association ${ }^{14}$ to learn what an elastic concept mental illness is. It ranges from the massive functional inhibition characteristic of one form of catatonic schizophrenia ${ }^{15}$ to those seemingly slight aberrancies associated with an emotionally unstable personality, ${ }_{10}^{16}$ but which are so close to conduct in which we all engage as to define the entire continuum involved. Obviously, the definition of mental illness is left largely to the user and is dependent upon the norms of adjustment that he employs. Usually the use of the phrase "mental illness" effectively masks the actual norms being applied. ${ }^{17}$ And, because of the unavoidably ambiguous generalities in which the American Psychiatric Association describes its diagnostic categories, the diagnostician has the ability to shoehorn into the mentally diseased class almost any person he wishes, for whatever reason, ${ }^{18}$ to put there.

All this suggests that the concept of mental illness must be limited in the field of civil commitment to a necessary rather than a sufficient condition for commitment. While the term has its uses, it is devoid of that purposive content that a touchstone in the law ought to have. Its breadth of meaning makes for such difficulty of analysis that it answers no question that the law might wish to ask. ${ }^{19}$

14 Diagnostic \& Statistical Manual of Mental Disorders (2d ed. 1968) [hereinafter cited as DSM-II]. The first edition of this manual, published in 1952, will be referred to as DSM-I.

15 DSM-II, 295.24 , at 33.

16 In such cases the individual reacts with excitability and ineffectiveness when confronted by minor stress. His judgment may be undependable under stress, and his relationship to other people is continuously fraught with fluctuating emotional attitudes, because of strong and poorly controlled hostility, guilt, and anxiety.

DSM-I, $000-x 51$, at 36 . In DSM-II, this disorder is characterized as hysterical personality. DSM-II, 301.5, at 43 .

17 "Normal and abnormal, one sometimes suspects, are terms which a particular anthor employs with reference to his own position on that curve." A. KINSEY, W. Pomeroy \& C. Martin, Sexual Behavior in the Human Maie 199 (1948). See also Boutilier v. Immigration \& Naturalization Service, 387 U.S. 118, 125 (1967) (Douglas, J., dissenting); W. SchofIELd, Psychotherapy: THE PURCHASE OF FRIENDSHIP 12-13 (1964); Weihofen, The Definition of Mental Illness, 21 OHIO ST. L.J. 1 (1960).

18 The usual reason for variance in diagnosis is a variance in the theoretical orientation of the diagnosticians.

19 We are not saying that mental illness does not exist or that the disease concept should not be used in the field of "functional" behavior disorders. Compare T. Szasz, The Mxth of Mental Irlness (1961); Albee, Models, Myths, and Manpower, 52 Mental Hygrene 168 (1968); Szasz, The Myth of Mental Illness, 15 Ax. PsycholoGIsT 113 (1960), werth Ausubel, Personality Disorder is Disease, 16 AM. PsychoroGIST 69 (1961); Meehl, Schizotaxia, Schizotypy, Schizophrenia, 17 AM. Psychologist 827 (1962); Meehl, Some Ruminations on the Validation of Clinical Procedures, 13 CAN. J. PsYcBoLOGY 102 (1959). The most objective and sophisticated methodological analysis known to us of the general problem of taxonomy, types, and disease entities in the domain of "non-organic" behavior disorders is Dahlstrom, Types and Personality Systematics, in Handooor of Modern PersonaltTy Theories (R. Cattell ed. [in press]). See also R. Cattell, Personality and Motivation, Structure and 


\section{Dangerousness to Others}

The element of dangerousness to others has, at least in practice, been similarly illusive. As Professors Goldstein and Katz have observed, such a test, at a minimum, calls for a determination both of what acts are dangerous and how probable it is that such acts will occur. $^{20}$ The first question suggests to a criminal lawyer the answer:

Measurement 382 (1957) ; M. Lorr, C. KLetT \& D. MCNaIR, Syndromes of Psychosis (1963); W. Mayer-Gross, E. Slater \& M. Roth, Clinicar Psychiatry 6 (2d ed. 1960); W. Sargant \& E. Slater, AN Introduction to Physical Methods of Treaturent In Psychratry 4, 14, 305 (4th ed. 1963); Cattell, Taxonomic Printciples for Locating and Using Types, in Formal REPRESENTATION OF HuMAN JuDGMENT 99 (B. Kleinmuntz ed. 1968); Foulds, Psychotic Depression and Age, 106 J. Mentat ScIENCE 1394 (1960); Kiloh \& Garside, The Independence of Neurotic Depression and Endogenous Depression, 109 BR. J. PSYchIATRY 451 (1963); McQuitty, Pattern Analysis Illustrated in Classifying Patients and Normals, 14 Educatronal \& Psychologicat MeAsurement 598 (1954); McQuitty, Typal Analysis, 21 EducaTroNal \& PSYChological MEasurentent 677 (1961); Meehl, Detecting Latent Clinical Taxa by Fallible Qucuntitative Indicators Lacking an Accepted Criterion, REP. PR-65-2, Research Laboratories, DeP'T of Psychiatry, Univ. of Minn. (1965); Meehl, Detecting Latent Clinical Taxa II: A Simplified Procednere, Some Additional Hitmax Cut Locators, a Single-Indicator Method, and Miscellaneous Theorems, ReP. PR-68-4, Research Laboratories, Dep't of Psychiatry, Univ. of Minn. (1968); Rao \& Slater, Multivariate Analysis Applied to Differences Between Nentotic Gronts, 2 Br. J. Psychology (Statisticar. Sect.) 17 (1949); Wender, On Necessary and Sufficient Conditions in Psychiatric Explanation, 16 ARCH. Gen. PsyCHIATRY 41 (1967); Wittenborn, Symptom Patterns in a Group of Mental Hospital Patients, 15 J. Consulting Psychology 290 (1951). See generally Explorations in TyPing PSYCHOTICS (M. Lorr ed. 1966) with its extensive bibliography. For a beautiful methodological analysis of the relation between specific etiology and other quantitative contributors-still very much worth reading in spite of the author's later repudiation of his substantive thesis-see S. FREUD, On the Grounds for Detaching a Particular Syndrome from Neurasthenia Under the Description "Anxiety Neurosis," and A Reply to Criticisms of $M y$ Paper on Anxiety Neurosis, in 3 CoMplete Psychological Works 90, 123 (J. Strachey ed. 1962).

Even a nodding acquaintance with these works should suffice to convince any scholar that the complexities are enormous, and that writers who find easy solutions to the disease-entity problem (e.g., with a few cliches about "pigeonholing" and "the unique individual") are not even beginning to grapple with it. A fair statement of the present situation in psychiatry and clinical psychology with regard to "disease entities" would be that nobody knows whether or not such entities exist outside the domain of the "organic" psychoses associated with demonstrable damage to the brain by trauma, toxins, infections, vascular disorder, senile changes, etc. The conceptual and statistical problems involved are difficult, recondite, and highly technical. We can only caution our law-trained readers against being "taken in" by plausible, quick and easy verbal resolutions of the issue, which are all too common among psychologists and psychiatrists. The most difficult class is the major functional disorders (e.g., schizophrenia, manic-depression) where hereditary factors appear to play an important causal role, but where the concept "disease" does not have quite its usual medical meaning. We do not think that the moral, policy and legal questions before us hinge upon the resolution of these empirical issues. The clinical status of a psychologically aberrated individual (e.g. "Can he think rationally about his condition?"), his prognosis (with and without hospitalization and treatment), and his probability of socially dangerous or intolerable conduct if left in the community are the relevant considerations. Given a particular quantitative balance among these three behavioral factors, what does it matter whether the behavior-syndrome is truly "taxonomic", and whether the aberration, taxonomic or not, is mainly attributable to germs, genes, toxins, or social learning experiences? It is, we submit, a mistake to rest the cases for and against civil commitment upon the slippery semantics of the term "disease," or upon the unsettled empirical questions concerning the etiology of mental disorder, as does Szasz.

20 Goldstein \& Katz, Dangeronsiness and Mental Illness: Some Observations on the Decision to Release Persons Acquitted By Reason of Insanity, 70 Y ALE L. J. 225, 235 (1960). See Note, The Nascent Right to Treatment, 53 U. VA. L. REv. 1134, 1141-43 (1967). 
crimes involving a serious risk of physical or psychical harm to another. Murder, arson and rape are the obvious examples. Even in criminal law, however, the notion of dangerousness can be much broader. If one believes that acts that have adverse effects on social interests are dangerous, and if one accepts as a generality that the criminal law is devoted to such acts, any crime can be considered dangerous. For example, speeding in a motor vehicle, although traditionally regarded as a minor crime, bears great risk to life and property, and thus may be viewed as a dangerous act. Dangerousness can bear an even more extensive definition as well. An act may be considered dangerous if it is offensive or disquieting to others. Thus, the man who walks the street repeating, in a loud monotone, "fuck, fuck, fuck," is going to wound many sensibilities even if he does not violate the criminal law. Other examples would be the man, found in most cities, striding about town lecturing at the top of his lungs, or the similar character in San Francisco who spends his time shadow boxing in public. If such people are dangerous, it is not because they threaten physical harm but because we are made uncomfortable when we see aberrancies. And, of course, if dangerousness is so defined, it is at least as broad a concept as mental illness. The cases are unfortunately silent about what meaning the concept of danger bears in the commitment process. ${ }^{21}$

Assuming that dangerousness can be defined, the problem of predictability still remains. For the man who can find sexual release only in setting fires, one may confidently predict that dangerous acts will occur. For the typical mentally aberrant individual, though, the matter of prediction is not susceptible of answer. However nervous a full-blown paranoiac may make us, there are no actuarial data indicating that he is more likely to commit a crime than any normal person. Should he engage in criminal activity, his paranoia would almost certainly be part of the etiology. But on a predictive basis we have, as yet, nothing substantial to rely on. ${ }^{22}$

21 But see United States v. Charnizon, 232 A.2d 586 (D.C. Ct. App. 1967), where the probability of the issuance of checks drawn on insufficient funds was found to render the defendant "dangerous."

22 While there is an inclination to equate mental illness and dangerousness, "the fact is that the great majority of hospitalized mental patients are too passive, too silent, too fearful, too withdrawn" to be dangerous. Statement of Albert Deutsch, Hearings on Constitutional Rights of the Mentally Ill Before the Subcomm. on Constitutional Rights of the Senate Comm. on the Judiciary, 87th Cong., 1st Sess. 43 (1961) [hereinafter cited as 1961 Hearings]. See also THE Clinical Evaluation of the Dangerousness of THe Mentally ILl (J. Rappeport ed. 1967); Statement of Thomas Szasz, 1961 Hearings 270; Dershowitz, Psychiatry in the Legal Process: $A$ Knife that Cuts Both Ways, 4 TRIAL, Feb./Mar. 1968 at 29; Giovannoni \& Gurel, Socially Disruptive Behavior of Ex-Mental Patients, 17 ARCH. GEN. PsychIATry 146 (1967); Rappeport \& Lassen, The Dangerousness of Female Patients: A Comparison of the Arrest Rate of Discharged Psychiatric Patients and the General Population, 123 Axr. J. Psychiatry 413 (1966); Weihofen, Institutional Treatment of Persons Acquitted by Reason of Insanity, 38 TEx. L. REv. 849, 855-7 (1960). 
Even if such information were available, it is improbable that it would indicate that the likelihood of crime within a group of individuals with any particular psychosis would be any greater than that to be expected in a normal community cross-section. ${ }^{23}$ Surely the degree of probability would not be as high as that in certain classes of convicted criminals after their release from prison or that in certain classes of persons having particular sociological or psychological characteristics.

\section{Dangerousness to Self}

The concept of "dangerousness to self" raises similar problems. The initial thought suggested by the phrase is the risk of suicide. But again it can be broadened to include physical or mental harm from an inability to take care of one's self, loss of assets from foolish expenditures, or even loss of social standing or reputation from behaving peculiarly in the presence of others. ${ }^{24}$ Again, if read very broadly this concept becomes synonymous with that of mental illness. And, of course, reliable prediction is equally impossible.

\section{In Need of Care, Custody, or Treatment}

The notion of necessity of care or treatment provides no additional limitation beyond those imposed by the concepts already discussed. One who is diagnosably mentally ill is, almost by definition, in need of care or treatment. ${ }^{25}$ Surely the diagnostician reaching the first conclusion would reach the second as well. And, if a man is dangerous, then presumably he is in need of custody. The problem, of course, lies with the word "need." If it is defined strictly as, for example, "cannot live without," then a real limitation on involuntary commitment is created. In normal usage, however, it is usually equated with "desirable," and the only boundary on loss of freedom is the value structure of the expert witness.

It is difficult to identify the reasons that lie behind incarceration of the mentally ill. Three seem to be paramount:

23 Of course, the probability of dangerous conduct would increase if the computation was made on the basis of a subclass comprised only of mentally ill individuals who had engaged in dangerous behavior before. Even here, though, we have no solid data upon which to rely.

24 E.g., Statement of Hugh J. McGee, 1961 Hearings 56. Another example of danger to self can be found in a woman enmeshed in a masochistic marriage. Not only may she suffer physical harm at the hands of her sadistic husband but her need for such sadism and her consequent willingness to endure it may lead to more serious psychical deterioration. See Snell, Rosenwald \& Robey, The Wife Beater's Wife-A Study of Fanily Interaction, 11 ARCH. GEN. Psychiatry 107 (1964).

25 That one needs treatment does not answer two other crucial questions: whether there is any known effective treatment for the affliction and whether treatment will be made available. 
(1) It is thought desirable to restrain those people who may be dangerous;

(2) It is thought desirable to banish those who are a nuisance to others;

(3) It is thought humanitarian to attempt to restore to normality and productivity those who are not now normal and productive.

Each of these goals has social appeal, but each also creates analytic difficulty.

As already mentioned, in order to understand the concept of danger one must determine what acts are dangerous and how likely is it that they will occur. There is a ready inclination to believe that experts in the behavioral sciences will be able to identify those members of society who will kill, rape, or burn. The fact is, however, that such identification cannot presently be accomplished. First, our growing insistence on privacy will, in all but a few cases, deny the expert access to the data necessary to the task of finding potential killers. Second, and of much greater importance, even if the data were available it is unlikely that a test could be devised that would be precise enough to identify only those individuals who are dangerous. Since serious criminal conduct has a low incidence in society, and since any test must be applied to a very large group of people, the necessary result is that in order to isolate those who will kill it is also necessary to incarcerate many who will not. Assume that one person out of a thousand will kill. Assume also that an exceptionally accurate test is created which differentiates with ninety-five per cent effectiveness those who will kill from those who will not. If 100,000 people were tested, out of the 100 who would kill 95 would be isolated. Unfortunately, out of the 99,900 who would not kill, 4,995 people would also be isolated as potential killers. ${ }^{26}$ In these circumstances, it is clear that we could not justify incarcerating all 5,090 people. If, in the criminal law, it is better that ten guilty men go free than that one innocent man suffer, how can we say in the civil commitment area that it is better that fifty-four harmless people be incarcerated lest one dangerous man be free?

The fact is that without any attempt at justification we have been willing to do just this to one disadvantaged class, the mentally ill. This practice must rest on the common supposition that mental illness makes a man more likely to commit a crime. While there may be some truth in this, there is much more error. Any phrase that en-

26 See Meehl \& Rosen, Antecedent Probability and the Effciency of Psychometric Signs, Patterns, or Cutting Scores, 52 PsychologICAI BULl. 194 (1955); Rosen, Detection of Suicidal Patients: An Example of Some Limitations in the Prediction of Infrequent Events, 18 J. Consulting Psychology 397 (1954). 
compasses as many diverse concepts as does the term "mental illness" is necessarily imprecise. While the fact of paranoid personality might be of significance in determining a heightened probability of killing, the fact of hebephrenic schizophrenia probably would not. Yet both fit under the umbrella of mental illness.

Even worse, we have been making assessments of potential danger on the basis of nothing as precise as the psychometric test hypothesized. Were we to ignore the fact that no definition of dangerous acts has been agreed upon, our standards of prediction have still been horribly imprecise. On the armchair assumption that paranoids are dangerous, we have tended to play safe and incarcerate them all. Assume that the incidence of killing among paranoids is five times as great as among the normal population. If we use paranoia as a basis for incarceration we would commit 199 non-killers in order to protect ourselves from one killer. ${ }^{27}$ It is simply impossible to justify any commitment scheme so premised. And the fact that assessments of dangerousness are often made clinically by a psychiatrist, rather than psychometrically and statistically, adds little if anything to their accuracy. ${ }^{28}$

We do not mean to suggest that dangerousness is not a proper matter of legal concern. We do suggest, however, that limiting its application to the mentally ill is both factually and philosophically unjustifiable. As we have tried to demonstrate, the presence of mental illness is of limited use in determining potentially dangerous individuals. Even when it is of evidentiary value, it serves to isolate too many harmless people. ${ }^{29}$ What is of greatest concern, however, is that the tools of prediction are used with only an isolated class of people. We have alluded before to the fact that it is possible to identify, on the basis of sociological data, groups of people wherein it is possible to predict that fifty to eighty per cent will engage in criminal or delinquent conduct. And, it is probable that more such classes could be identified if we were willing to subject the whole population to the various tests and clinical examinations that we now impose only on those asserted to be mentally ill. Since it is perfectly obvious that society would not consent to a wholesale invasion of privacy of this

27 Even if we applied the psychometric test earlier hypothesized to a group of paranoids, we would still isolate ten harmless individuals for every dangerous one.

28 See note 4 supra.

29 This is compounded by the natural inclination of institutional psychiatrists and committing courts to protect themselves against possible censure by retaining patients until any possibility of danger has passed. See, e.g., Ragsdale v. Overholser, 281 F.2d 943 (D.C. Cir. 1960). This conclusion is reinforced by a study to which Dr. Guttmacher alluded, 1961 Hearings 152, when he said that "people who were released against hospital advice made about as good an adjustment rate as the people who were released by the hospital." See also Lewin, Disposition of the Irresponsible: Protection Following Commitment, 66 MrCH. L. REv. 721 (1968). 
sort and would not act on the data if they were available, we can conceive of no satisfactory justification for this treatment of the mentally ill.

One possible argument for different treatment can be made in terms of the concept of responsibility. ${ }^{30}$ We demonstrate our belief in individual responsibility by refusing to incarcerate save for failure to make a responsible decision. Thus, we do not incarcerate a group, eighty per cent of whom will engage in criminal conduct, until those eighty per cent have demonstrated their lack of responsibility-and even then, the rest of the group remains free. The mentally diseased, so the argument would run, may be viewed prospectively rather than retrospectively because for them responsibility is an illusory concept. We do not promote responsibility by allowing the dangerous act to occur since, when it does, we will not treat the actor as responsible. One way of responding to this is to observe that criminal responsibility and mental illness are not synonymous, and that if incarceration is to be justified on the basis of irresponsibility, only those mentally ill who will probably, as a matter of prediction, commit a crime for which they will not be held responsible should be committed. ${ }^{31}$ A more fundamental response is to inquire whether susceptibility to criminal punishment is reasonably related to any social purpose. Granted that there is a gain in social awareness of individual responsibility by not incarcerating the responsible in advance of their crime, it does not necessarily follow that it is sufficiently great to warrant the markedly different treatment of the responsible and the irresponsible.

The other possible justification for the existing differential is that the mentally diseased are amenable to treatment. We shall explore the ramifications of this at a later point. It is sufficient now to observe that there is no reason to believe that the mentally well, but statistically dangerous, individual is any less amenable to treatment, though that treatment would undoubtedly take a different form.

Another basis probably underlying our commitment laws is the notion that it is necessary to segregate the unduly burdensome and the social nuisance. Two cases typify this situation. The first is the senile patient whose family asserts inability to provide suitable care. At this juncture, assuming that the family could put the person on the street where he would be unable to fend for himself, society must act to

30 See Note, Civil Connnitnent of the Mentally Ill: Theories and Procedures, 79 Harv. L. Rev. 1288, 1290 (1966); Project, Civil Commitment of the Mentally Ill, 14 U.C.L.A. L. REv. 822,827 (1967).

31 It would be even more difficult to predict irresponsibility than it is to predict dangerous conduct. In addition, it is unlikely that the irresponsible will represent. a high percentage of the mentally ill. See Livermore \& Meehl, The Virtues of M'Naghten, 51 MINN. L. Rev. 789 (1967). 
avoid the unpleasantness associated with public disregard of helplessness. This caretaking function cannot be avoided. Its performance, however, is a demonstration of the psychological truth that we can bear that which is kept from our attention. Most of us profess to believe that there is an individual moral duty to take care of a senile parent, a paranoid wife, or a disturbed child. Most of us also resent the bother such care creates. By allowing society to perform this duty, masked in medical terminology, but frequently amounting in fact to what one court has described as "warehousing," 32 we can avoid facing painful issues.

The second case is the one in which the mentally ill individual is simply a nuisance, as when he insists on sharing his paranoid delusions or hallucinations with us. For reasons that are unclear, most of us are extremely uncomfortable in the presence of an aberrant individual, whether or not we owe him any duty, and whether or not he is in fact a danger to us in any defensible use of that concept. Our comfort, in short, depends on his banishment, and yet that comfort is equally dependent on a repression of any consciousness of the reason for his banishment. It is possible, of course, to put this in utilitarian terms. Given our disquietude, is not the utility of confinement greater than the utility of liberty? Perhaps so, but the assertions either that we will act most reasonably if we repress thinking about why we are acting or, worse yet, that our legislators will bear this knowledge for us in order to preserve our psychic ease make us even more uncomfortable than the thought that we may have to look mental aberrance in the eye.

Again, we do not wish to suggest that either burden or bother is an inappropriate consideration in the commitment process. What we do want to make clear is that when it is a consideration it ought to be advertently so. Only in that way can intelligent decisions about care, custody, and treatment be made.

The final probable basis for civil commitment has both humanitarian and utilitarian overtones. When faced with an obviously aberrant person, we know, or we think we know, that he would be "happier" if he were as we are. We believe that no one would want to be a misfit in society. From the very best of motives, then, we wish to fix him. It is difficult to deal with this feeling since it rests on the unverifiable assumption that the aberrant person, if he saw himself as we see him, would choose to be different than he is. But since he cannot be as we, and we cannot be as he, there is simply no way to judge the predicate for the assertion.

32 Sas v. Maryland, 334 F.2d 506, 516 (4th Cir. 1963). 
Our libertarian views usually lead us to assert that treatment cannot be forced on anyone unless the alternative is very great social harm. Thus while we will require smallpox vaccinations ${ }^{33}$ and the segregation of contagious tuberculars, we will not ordinarily require bed rest for the common cold, or a coronary, or even require a pregnant woman to eat in accordance with a medically approved diet. Requiring treatment whenever it seemed medically sound to do so would have utilitarian virtues. Presumably, if death or serious incapacitation could thereby be avoided society would have less worry about unsupported families, motherless children, or individuals no longer able to support themselves. Similarly, if the reasoning were pursued, we could insure that the exceptionally able, such as concert violinists, distinguished scholars, and inspiring leaders would continue to benefit society. Nonetheless, only rarely does society require such treatment. ${ }^{34}$ Not only does it offend common notions of bodily integrity and individual autonomy, but it also raises those issues of value judgment which, if not insoluble, are at least discomforting. For example, is the treatment and cure of the mentally ill individual of more benefit to society than the liberty of which he is deprived and the principle (lost, or tarnished) that no one should assert the right to control another's beliefs and responses absent compelling social danger?

The reason traditionally assigned for forcing treatment on the mentally ill while making it voluntary for other afflicted persons is that the mentally ill are incapable of making a rational judgment whether they need or desire such help..$^{35}$ As with every similar statement, this depends on what kind of mental illness is present. It is likely that a pederast understands that society views him as sick, that certain kinds of psychiatric treatment may "cure" him, and that such treatment is available in certain mental institutions. It is also not unlikely that he will, in these circumstances, decide to forego treatment, at least if such treatment requires incarceration. To say that the pederast lacks insight into his condition and therefore is unable to intelligently decide whether or not to seek treatment is to hide our real judgment that he ought to be fixed, like it or not. ${ }^{36}$ It is true that some mentally ill

33 Jacobson v. Massachusetts, 197 U.S. 11, 27 (1905) : "Upon the principle of self-defense, of paramount necessity, a community has the right to protect itself against an epidemic of disease which threatens the safety of its members."

34 See generally, Note, Compulsory Medical Treatment, 51 Minn. L. REv. 293 (1966).

35 See generally Slovenko, The Psychiatric Patient, Liberty and the Law, 13 Kan. L. REv. 59 (1964); Note, Civil Commitment of Narcotics Addicts, 76 YALE L, J. 1160, 1168-1174 (1967); Note, Civil Commitment of the Mentally Ill: Theories and Procedures, 79 HARV. L. REv. 1288, 1295-98 (1966).

36 The circularity of argument is obvious when the refusal to accept treatment is used as evidence of incompetence to decide, which in turn justifies compulsion. It is 
people may be unable to comprehend a diagnosis and, in these instances, forced treatment may be more appropriate. But this group is a small proportion of the total committable population. Most understand what the clinician is saying though they often disagree ${ }^{37}$ with his view.

We have tried to show that the common justifications for the commitment process rest on premises that are either false or too broad to support present practices. This obviously raises the question of alternatives. Professor Ehrenzweig has suggested in another context that the definition of mental illness ought to be tailored to the specific social purpose to be furthered in the context in question. ${ }^{38}$ That is what we propose here.

Returning to the first of our considerations supporting commitment, we suggest that before a man can be committed as dangerous it must be shown that the probabilities are very great that he will commit a dangerous act. Just how great the probabilities need be will depend on two things: how serious the probable dangerous act is and how likely it is that the mental condition can be changed by treatment. A series of hypotheticals will indicate how we believe this calculus ought to be applied.

Case 1: A man with classic paranoia exhibits in clinical interview a fixed belief that his wife is attempting to poison him. He calmly states that on release he will be forced to kill her in self defense. The experts agree that his condition is untreatable. Assume that statistical data indicate an eighty per cent probability that homicide will occur. If society will accept as a general rule of commitment, whether or not mental illness is present, that an eighty per cent probability of homicide is sufficient to incarcerate, then this man may be incarcerated. In order to do this, of course, we must be willing to lock up twenty people out of 100 who will not commit homicide.

Case 2: Assume the same condition with only a forty per cent probability of homicide. ${ }^{39}$ We do not know whether,

also present, however, in more refined formulations suggesting that mental illness diminishes liberty and that "mental health treatment should be required when the increase in liberty resulting from treatment outweighs the limitations necessary for the therapeutic process." Comment, Liberty and Required Mental Health Treatment, 114 U. PA. L. REv. 1067 (1966). The circularity is buried even deeper when incompetence to decide is premised on a psychiatric judgment that while the proposed patient cognitively appreciates the nature of the decision, his emotional response or affect is inappropriate.

37 See, e.g., M. Twain, The Mysterious Stranger passim (1916).

38 Ehrenzweig, $A$ Psychoanalysis of the Insanity Plea-Chues to the Problems of Criminal Responsibility and Insanity in the Death Cell, 73 YaLE L.J. 425 (1964).

30 The case becomes even more interesting when the condition is usually compensated, thus making the individual a functioning member of society, but can on rare occasions become briefly decompensated with possibly disastrous results. Consider the case of the man who over a period of 15 years had two episodes of catatonic excitement in which he became violently assaultive. Each occurrence came without warning. 
if the condition is untreatable, commitment is justified in these circumstances. If lifetime commitment is required because the probabilities are constant, we doubt that the justification would exist. Our own value structure would not allow us to permanently incarcerate sixty harmless individuals in order to prevent forty homicides. On the other hand, if incarceration for a year would reduce the probability to ten per cent, then perhaps it is justified. Similarly, if treatment over the course of two or three years would substantially reduce the probability, then commitment might be thought proper.

Case 3: A man who compulsively engages in acts of indecent exposure has been diagnosed as having a sociopathic personality disturbance. The probability is eighty per cent that he will again expose himself. Even if this condition is untreatable, we would be disinclined to commit. ${ }^{40}$ In our view, this conduct is not sufficiently serious to warrant extended confinement. For that reason, we would allow confinement only if "cure" were relatively quick and certain.

The last case probably is more properly one of nuisance than of danger. The effects of such conduct are offensive and irritating but it is unlikely that they include long-term physical or psychical harm. That does not mean, however, that society has no interest in protecting its members from such upset. Again, the question is one of alternatives. Much nuisance behavior is subject to the control of the criminal law or of less formal social restraints. In mental institutions patients learn that certain behavior or the recounting of delusions or hallucinations will be met with disapproval. ${ }^{41}$ Accordingly, they refrain from such behavior or conversation. There is no reason to believe that societal disapproval in the form of criminal proscriptions or of less formal sanctions will be less effective as a deterrent. ${ }^{42}$ And, from our standpoint, the liberty of many mentally ill individuals is worth far more than the avoidance of minor nuisances in society.

Case 4: A person afflicted with schizophrenia walks about town making wild gestures and talking incessantly. Those who view him are uncomfortable but not endangered. We doubt that commitment is appropriate even though it would promote the psychic ease of many people. Arguably

40 It should be pointed out, however, that such conduct would most probably violate the criminal law, so that criminal prosecution and incarceration might be in order, even though civil commitment would be improper.

41 See E. Gofrman, Asylums (1961).

42 For example, a bus driver in Minneapolis began to annoy passengers by inflicting his paranoid ideas on them in conversation. He was advised by his employer that if he continued to do this, he would lose his employment. The offensive conduct stopped and the driver continued to work for many more years. 
we would all be happier if our favorite bogey man, whether James Hoffa, Rap Brown, Mario Savio, or some other, were incarcerated. Most of us would be outraged if any of these men were committed on such a theory. If we cannot justify such a commitment in these cases, we doubt that it is any more justifiable when social anxiety is a consequence of seeing mentally ill individuals. While it might be proper to commit if speedy cure were possible, such cures are, as a matter of fact, unavailable. Moreover, we have some difficulty distinguishing the prevention of psychic upset based on cure of the mentally ill and prevention based on netatralizing other upsetting behavior. ${ }^{43}$

The next justification of commitment is more solid, though it too presents the question of the necessity of utilizing less burdensome alternatives. This is the rationale of care for the person who is unable to care for himself and who has no one else to provide care for him. As we suggested earlier, such care must be provided if we are unwilling to allow people to die in the streets.

Case 5: An elderly woman with cerebro-vascular disease and accompanying cerebral impairment has the tendency to leave her home, to become lost, and then to wander helplessly about until someone aids her. ${ }^{44}$ At other times she is perfectly able to go shopping or visit friends. She has no relatives who will care for her in the sense that they will prevent her from wandering or will find her when she has become lost. In some ways, this is another case of a public nuisance and it may well be that it is impossible to find a justification for incarcerating this woman. On the other hand, to allow this woman to die from exposure on one of her forays is as disquieting as the loss of her freedom. Since her condition is untreatable, provision of treatment offers no justification for confinement. It might be justifiable to exercise some supervision over her, but surely that justifica-

43 The most famous case of incarceration to relieve psychic anxiety is the segregation of the Japanese in World War II. See Ex parte Endo, 323 U.S. 283 (1944); Korematsu v. United States, 323 U.S. 214 (1944). This episode, however, has never been cited as one that had favorable precedential value. See Rostow, The Japanese American Cases-A Disaster, 54 Yale L.J. 489 (1945).

A statute in the District of Columbia, D.C. CoDE \$24-301(d) (1961), providing for mandatory commitment after acquittal by reason of insanity was passed in part to add to "the public's peace of mind." Lynch v. Overholser, 369 U.S. 705, 717 (1962), quoting S. REP. No. 1170, 84th Cong., 1st Sess. 13 (1955); H.R. REP. No. 892, 84th Cong., 1st Sess. 13 (1955). In the case of Bolton v. Harris, 395 F.2d 642 (D.C. Cir. 1968), the mandatory commitment provision was attacked as failing to provide equal protection of the laws. Judge Bazelon agreed, but instead of holding the entire provision invalid, the court merely read the procedural safeguards of the civil commitment statute into subsection (d). See Comment, Commitment Following Acquittal by Reason of Insanity and the Equal Protection of the Laws, 116 U. PA. L. REv. 924 (1968). See also Moder Penal Code \$ 4.08, Comment (Tent. Draft No. 4, 1955).

44 See Lake v. Cameron, 364 F.2d 657 (D.C. Cir. 1966). 
tion will not support total incarceration. In these circumstances, we believe that if the state wishes to intervene it must do so in some way that does not result in a total loss of freedom. ${ }^{45}$ The desire to help ought not to take the form of simple jailing.

Case 6: A schizophrenic woman is causing such an upset in her family that her husband petitions for commitment. It is clear that the presence of this woman in the family is having an adverse effect on the children. Her husband is simply unwilling to allow the situation to continue. The alternatives here are all unpleasant to contemplate. If the husband gets a divorce and custody, he may accomplish his end. But the social opprobrium attaching to that solution makes it unlikely. The question, then, is whether the state should provide a socially acceptable alternative. If that alternative is her loss of freedom, we find it hard to justify. Assuming that the condition is untreatable, that the woman is not dangerous, and that her real sin is her capacity to disrupt, it is almost incomprehensible that she should be subject to a substantial period of incarceration. Yet that is what it has meant. Presumably, in order to isolate the woman from her family, it is necessary to transport her to a location where she will no longer bother her family. Then, if she is able to support herself she could have complete freedom. If she is not able, the state will have to provide care. That care, of course, need not involve a total deprivation of freedom. ${ }^{46}$

The final justification for commitment-the need to treat-is in many ways the most difficult to deal with. As we have said before, society has not traditionally required treatment of treatable diseases even though most people would agree that it was "crazy" for the diseased person not to seek treatment. ${ }^{47}$ The problem has been complicated by the fact that religious beliefs against certain forms of treatment often are present ${ }^{48}$ and by the fact that most cases of stubborn refusal to accept treatment never come into public view. ${ }^{49}$ There is, however, a competing analogy that suggests that mandatory treatment may sometimes be appropriate.

45 Id. See also Association of the Bar of the City of New York, Mental Illness ANd DUe Process 43 (1962).

46 If nothing short of total confinement can keep the woman away from her family, we may have to temporarily deprive her of all freedom. If this occurs frequently enough, deterrence may be effected. If that, too, fails, then long term confinement may be necessary, barbaric as that may seem. Obviously, the disruption ought to be very great before this last alternative is embraced.

47 See note 34 supra and accompanying text.

48 E.g. Jehovah's Witnesses v. King County Hosp., 278 F. Supp. 488 (W.D. Wash. 1967).

40 See In Mesnory of Mr. Justice Jackson, 349 U.S. xxvii, xxix (1955). 
Without going into unnecessary detail, we think it can be said that one of the reasons society requires compulsory education is that it believes a certain minimum amount of socialization is necessary for everyone lest they be an economic burden or a personal nuisance. ${ }^{50}$ That principle can also be used to support mandatory psychiatric rewiring if the individual to be refurbished is in fact a burden or nuisance and can be fixed. The difficulty, of course, lies in the extent to which the principle can be carried. To take a mild example outside the field of mental disease, assume an unemployable individual who is unable to support his large and growing family. Could society incarcerate him until he had satisfactorily acquired an employable skill? ${ }^{51}$ In the context of mental disease, then, can society demand that an individual obtain an employable psyche?

Case 7: An individual has been suffering from paranoid schizophrenia for several years without remission and has lost his job because of his behavior. He is divorced, but he is able to support himself from prior savings. He is not dangerous, and if he is committed it is unlikely that he will be cured since the recovery rates from such long-term schizophrenia are very low. ${ }^{52}$ In addition, the availability of treatment in a state mental institution is problematic. ${ }^{53}$

60 "A primary purpose of the educational system is to train school children in good citizenship, patriotism and loyalty to the state and the nation as a means of protecting the public welfare." In re Shinn, 195 Cal. App. 2d 683, 686, 16 Cal. Rptr. 165, 168 (Dist. Ct. App. 1961). See also State v. Superior Court, 55 Wash. $2 \mathrm{~d} 177,346$ P.2d 999 (1959), cert. denied, 363 U.S. 814 (1960).

51 Consider the comment of the Minnesota court in Leavitt v. City of Morris, 105 Minn. 170, 175, 117 N.W. 393, 395 (1908): "The state has the power to reclaim submerged lands, which are a menace to the public health, and make them fruitful. Has it not, also, the power to reclaim submerged men, overthrown by strong drink, and help them to regain self-contro1?" But see Golding, Ethical Issies in Biological Engineering, 15 U.C.L.A. L. REv. 443 (1968).

52 See, e.g., Drasgow, A Criterion for Chronicity in Schizophrenia, 31 PsYchIATRIC Q. 454 (1957).

53 That a certain form of treatment is useful in one type of case, of course, does not mean it is uniformly efficacious or even helpful with respect to all mental illnesses. Thus, while milieu therapy, the provision of a structured environment, may be a positive benefit to a psyche that must be removed from existing pressures or stresses, it may be useless or even harmful in other cases requiring other forms of treatment. We applaud the humanitarian concern of the Court of Appeals for the District of Columbia in recognizing a right to treatment in Rouse v. Cameron, 373 F.2d 451 (D.C. Cir. 1966), but we view that effort as misconceived. It suggests that if a patient is receiving any treatment, the state may continue his commitment. This can only be so if the provision of treatment is itself a basis of commitment, a proposition that we find horrifying in its implications. It also tends to direct attention to the limited question of provision of treatment rather than to the more fundamental question whether the state may incarcerate. Finally, by necessity it requires assessment of adequacy of treatment, an issue that because the treating professionals are in disagreement, the courts are ill-equipped to judge. See generally Commonwealth v. Page, 339 Mass. 313, 159 N.E.2d 82 (1959) ; Position Statement on the Adequacy of Treatment, 123 Ax. J. Psychiatry 1458 (1967); Note, Civil Restraint, Mental Illness, and the Right to Treatment, 77 YALE L.J. 87 (1967); Note, Due Process for All-Constitutional Standards for Involuntary Civil Commitment and Release, 34 U. CaI. L. REY. 633 (1967); Note, The Nascent Right to Treatment, 53 U. VA. L. REV. 1134 (1967). 
We doubt that he can justifiably be committed. If treatment is an adequate basis for confinement, it surely ceases to be so either when the illness is untreatable or when treatment is in fact not given or given in grossly insufficient amounts. No other basis for commitment being present, it is unjustifiable.

Case 8: A distinguished law school professor, known for a series of brilliant articles, is suffering from an involutional depression. His scholarship has dried up, and, while he is still able to teach, the spark is gone and his classes have become extremely depressing. There is a chance, though probably not more than twenty-five per cent, ${ }^{54}$ that he will commit suicide. He has been told that he would recover his old élan if he were subjected to a series of electro-shock treatments but this he has refused to do. In fact, in years past when he was teaching a course in law and psychology, he stated that if he ever became depressed he wanted it known that before the onset of depression he explicitly rejected such treatment. Should he be compelled to undergo treatment? The arguments of social utility would suggest that he should. Yet we are unable to dislodge the notion that potential added productivity is not a license for tampering.

Case 9: A woman suffers from a severe psychotic depression resulting in an ability to do little more than weep. Again shock treatment is recommended with a reasonable prospect of a rapid recovery. The woman rejects the suggestion saying that nothing can make her a worthy member of society. She is, she claims, beyond help or salvation. It is possible to distinguish this from the preceding case on the ground that her delusional thought processes prevent her from recognizing the desirability of treatment. But any distinction based on a proposed patient's insight into her condition will probably be administered on the assumption that any time desirable treatment is refused, insight is necessarily lacking. And that, of course, would destroy the distinction.

These cases suggest that the power to compel treatment is one that rarely ought to be exercised. We are unable to construct a rationale that will not as well justify remolding too many people to match predominant ideas of the shape of the ideal psyche. We recognize, of course, that we are exhibiting a parade of horrors. In this instance, however, we believe such reference justified. The ease with which one can be classified as less than mentally healthy, and the difficulty in distinguishing degrees of sickness, make us doubt the ability of anyone to judge when the line between minimum socialization 
and aesthetically pleasing acculturation has been passed. Regardless of our views, however, it seems clear that if society chooses to continue to exercise the power to compel treatment, it ought to do so with constant awareness of the threat to autonomy thus posed.

Different considerations are present when commitment is not based on the need to treat. If one is committed as dangerous, or as a nuisance, or as unable to care for oneself, and treatment can cure this condition, then it is easier to strike the balance between deprivation of liberty and the right to refuse treatment in favor of compulsory treatment. If told that this is the price of freedom, the patient may accede; if he prefers confinement to treatment, perhaps the state ought not to override his wishes. But at least in this situation the question is ethically a close one.

The difficulty with present commitment procedures is that they tend to justify all commitments in terms that are appropriate only to some, and to prescribe forms of treatment that are necessary in only some cases. Thus, while danger stemming from mental illness may be a proper basis for commitment, it does not follow that all mentally ill are dangerous, or that the standards of danger should be markedly less rigid in cases of mental illness. Similarly, because mentally ill people may be a nuisance and some means of preventing such nuisance must be found, it does not follow that nuisance commitments ought to involve the same restraints as commitments based upon potential danger. Finally, because treatment is humanitarian when applied to those confined for danger, nuisance, or care, does not in itself suggest that treatment can be applied whenever administrators believe it proper or humane to do so.

We recognize that many people will not agree with the manner in which we have drawn the balance in individual cases. We hope that few will disagree that the balance must be drawn. We suggest, therefore, that in each case of proposed commitment, the following questions be asked:

I. What social purpose will be served by commitment?

A. If protection from potential danger, what dangerous acts are threatened? How likely are they to occur? How long will the individual have to be confined before time or treatment will eliminate or reduce the danger so that he may be released? ${ }^{55}$

B. If protection from nuisance, how onerous is the nuisance in fact? Ought that to justify loss of freedom? 
If it should, how long will confinement last before time or treatment will eliminate or reduce the risk of nuisance so that release may occur?

C. If the need for care, is care in fact necessary? If so, how long will confinement last before time or treatment will eliminate the need for care so that release may occur?

II. Can the social interest be served by means less restrictive than total confinement?

III. Whatever standard is applied, is it one that can comfortably be applied to all members of society, mentally ill or healthy? ${ }^{56}$

IV. If confinement is justified only because it is believed that it will be of short term for treatment, is the illness in fact treatable? If it is, will appropriate treatment in fact be given?

If these questions are asked-and we view it as the duty of the attorney for the potential patient to insure that they are-then more intelligent commitment practices may follow. ${ }^{57}$

56 See Morris, Impediments to Penal Reform, 33 U. CHr. L. REv. 627, 640 (1966).

57 The proposed statutory formulation that most nearly approaches ours is contained in Royal Commassion on the Law Retating to Mental IllNess aNd Mental DeFiCIENCY, 1954-1957, REPORT, CMD. No. 169, at 111 (1957):

We consider that the use of special compulsory powers on grounds of the patient's mental disorder is justifiable when:-

(a) there is reasonable certainty that the patient is suffering from a pathological mental disorder and requires hospital or community care; and

(b) suitable care cannot be provided without the use of compulsory powers; and

(c) if the patient himself is unwilling to receive the form of care which is considered necessary, there is at least a strong likelihood that his unwillingness is due to a lack of appreciation of his own condition deriving from the mental disorder itself; and

(d) there is also either

(i) good prospect of benefit to the patient from the treatment proposed-an expectation that it will either cure or alleviate his mental disorder or strengthen his ability to regulate his social behaviour in spite of the underlying disorder, or bring him substantial benefit in the form of protection from neglect or exploitation by others; or

(ii) a strong need to protect others from anti-social behaviour by the patient. 